\title{
A Genre Analysis of English and Iranian Research Articles Abstracts in Applied Linguistics and Mathematics
}

\author{
Biook Behnam \\ Department of English, College of Persian Literature and Foreign Languages, Tabriz Branch, Islamic Azad University, Tabriz, Iran \\ Farhad Golpour (Corresponding author) \\ Department of English, Ahrar Institute of Technology and Higher Education, Rasht, Iran \\ E-mail: golpourf@gmail.com
}

Received: 20-03-2014

Accepted: 14-05-2014

Published: 01-09-2014

doi:10.7575/aiac.ijalel.v.3n.5p.173

URL: http://dx.doi.org/10.7575/aiac.ijalel.v.3n.5p.173

\begin{abstract}
In recent years, genre studies have attracted the attention of many researchers. The aim of the present study was to observe the differences in generic structure of abstract written by English native and non-native (Iranian) students in two disciplines of mathematics and applied linguistics. To this end, twenty native English students' abstract texts from each discipline and the same number of non-native (Iranian) ones were selected. In this study, Hyland's (2000) five-move model was used to identify the rhetorical structure of the four sets of texts. After analyzing each text, the main moves were extracted and the frequencies of each one were calculated and compared. The cross-disciplinary and cross-linguistic analyses reveal that linguistics abstracts follow a conventional scheme, but mathematics abstracts in these two languages do not exhibit the usual norms in terms of moves. Besides, greater difference in move structure is seen across languages in mathematics. The findings of the study have some pedagogical implications for academic writing courses for graduate students, especially students from non-English backgrounds in order to facilitate their successful acculturation into these disciplinary communities.
\end{abstract}

Keywords: Genre Analysis, mathematics, applied linguistics

\section{Introduction}

As a result of the shortcomings of register and discourse analysis, in recent years there has been attention to genre centered approaches such as analysis of written and spoken discourse in the applied linguistics field. The purpose behind these researches has been providing all-inclusive models for English non-native speaker students, regarding different genes of their disciplines. Looking at genre in a new perspective separated it from traditional view that genre was used for text classification. The most influential impact of the genre in applied linguistics derived from the works of John Swales and others who investigated the use of English in academic and professional settings (Swales, 1987, 1990; Bhatia, 1993). According to Hyland (2003) being aware of rhetorical structures of different genres is helpful for ESP teachers because they can grasp how language is used in various contexts. One of the research lines in genre studies received extensive attention from researchers is move analysis. According to Nwogu (1997) move analysis in genre studies is the identification of schematic units or moves. Most studies have focused on the analysis of the organizational patterns of RA sections in terms of their constituent moves, such as the study of the introduction section (Samraj, 2002, 2005; Swales, 1990, 2004), the methods section (Lim, 2006), the results section (Taylor \& Chen, 1991; Yang \& Allison, 2003 Atai,2012), and the discussion section (e.g., Yang \& Allison, 2003). Moreover, some studies have focused on sentence analysis such as the uses of hedging (Hyland, 1996), modality (Salager-Meyer, 1992), personal pronouns (Pho, 2008), and citations (Swales, 1990) and dissertation acknowledgement.

Some studies are elaborated here in details. Giannoni (2002) compared 100 acknowledgement texts of research articles to investigate textualization of scholarly acknowledgement in English and Italian journals from a genre- analytic view. Difference or similarities between features of corpora and culture are investigated in term of generic complexity and pragmatic appropriateness. The findings indicate that generic frameworks mirror linguistic borders but also writers follow the national patterns that the communities merit.

Peacook (2002) accomplished a research on research articles and examined the communicative moves in discussion sections across different disciplines including hard science as physics, environmental science, biology, business and soft science such as language and linguistics, social administration, public, and law with overall corpus of 242 RAs. In this study he utilized the Dudley- Evans model, and he discovered some new moves and move cycle not found by DudleyEvans and also discovered a number of differences in the main part that is evaluation.

Hyland (2003) investigated the generic structure of dissertation acknowledgement texts written by Contones and Mandarin speakers writing in English. He discovered that the acknowledgements are complicated textual constructs that include the public, personal, social, professional, academic and moral features. 
Golpour (2011) analyzed acknowledgment texts of dissertations based on Hyland's (2002) model. In this study the main moves and their steps were recognized and the frequencies of each one were calculated and compared. He discovered a new step called "thanking God' step'. And the difference in using this step between native and non-native students was statistically significant, it means that non-native (Iranian) students used this step more than native ones .

Salvager-Meyer (1990) investigated 77 medical English abstracts of three text types of case reports, research papers and review articles. He identified six moves for the generic organization of medical research article abstracts. They are: Statement-Purpose-Corpus/Methods-Results-Conclusion-Recommendation. Graetz (1985) studied 87 abstracts and determined the rhetorical structure of RA abstracts as Problem-Method-Results-Conclusion. Bhatia (1993) in his work of Language Use in Professional Settings identifies four moves in RA abstracts: (a) Introducing Purpose, (b) Describing Methodology, (c) Summarizing Results, (d) Presenting Conclusions. Stein (1998) studies the conference abstract of "Teaching English to the Speakers of Other Languages" (TESOL) in terms of its rhetorical function. It is found that abstracts can be classified into empirical abstracts and pedagogical abstracts. The empirical abstracts consist of four moves: Introduction-Method-Results-Discussion (IMRD), while the pedagogical abstracts fail to conform to the IMRD pattern, which includes only three moves of Introduction, Lecture and Final.

Key Hyland (2000) investigates the writer's statement of the research purpose from the Introduction section, categorizing the abstracts as Introduction, Purpose, Method, Result and Conclusion. Martin (2003) investigated the rhetorical variation between the research article abstracts written in English for international journals in the area of experimental social science. For this purpose 160 research article abstracts written in English and Spanish has been selected. The findings revealed that the rhetorical structure of abstracts written in Spanish in the area of experimental social sciences generally reflects the international. However, some degrees of differences have been observed in the frequency of occurrence of the result part and move 2 in the abstract introductions.

Indeed, there are some studies that investigated the schematic construction of abstracts written by native and non-native writers but to the researchers' domain of knowledge, not specific study was done to compare move structure of abstracts in two disciplines of mathematics and applied linguistics in Iran. The main purpose of this study was to find differences and similarities in type and frequency of move structure of research article abstracts written by English native and nonnative (Iranian) students in applied linguistic and mathematics.The findings of the present study can be helpful to ESP, EFL and EAP teachers to instruct their novice students these schematic pattern and students, in turn, can utilize the discovered model in their abstract writing.

This study aims to answer following research questions:

1. Is there any difference between type and frequency of move structure of research article abstracts written by English native and non-native (Iranian) students in applied linguistics?

2. Is there any difference between type and frequency of move structure of research article abstracts written by English native and non-native (Iranian) students in Mathematics?

Based on the above questions the following null hypotheses were constructed:

1. There is no difference between type and frequency of move structure in research article abstracts written by English native and non-native (Iranian) students in applied linguistics.

2. There is no difference between type and frequency of move structure in research article abstracts written by English native and non-native (Iranian) students in mathematics.

\section{Corpus}

The texts in our data set include in total $80 \mathrm{RA}$ abstracts as shown in Table 1 from two disciplines, linguistics and mathematics, in two languages English and Persian. According to Hyland (2000) Linguistics belongs to the social science or "soft discipline and mathematics has to do with the natural science or "hard discipline

Table 1. Four Groups of Abstracts

\begin{tabular}{lll}
\hline Moves & Linguistics & mathematics \\
\hline English & Applied Linguistics (AL) & Journal of American \\
& & Mathematical Studies (JAMS) \\
Persian & Iranian Applied linguistics journal & $\begin{array}{l}\text { Iranian Journal of Mathematical Sciences } \\
\text { and Informatics(IJMSI) }\end{array}$ \\
& (IJAL) & \\
\hline
\end{tabular}

Research article(RA) abstracts were randomly chosen from recent publication journals in their respective fields. The RA abstracts in the data set were published between 2008 and 2013.The English texts include 40 RA abstracts published in the United States: 20 was selected from an international journal of Applied Linguistics (AL) and20 from an international mathematics Journal of American Mathematical Studies (JAMS)

Likewise, the Iranian texts constitute 40 RA abstracts published in Iran: 20 from linguistics Iranian Applied linguistics journal (IJAL) and 20 from Iranian Journal of Mathematical Sciences and Informatics (IJMSI). All selected abstracts from linguistic journals were from the field of applied linguistics, and the mathematic abstracts organic mathematics. 


\subsection{The analytical framework}

In this study, Hyland's (2000) five-move model was used to identify the rhetorical structure of the four sets of texts. Each move performs a specific function. According to this model, the five moves are: Introduction (M1), Purpose (M2), Method (M3), Product (M4), and Conclusion (M5). As shown in Table 2, each move represents the realization of a communicative goal (Hyland, 2000). In contrast to the traditional IMRD model, he differentiated the writer's purpose from the introduction move, where it is often found.

Table 2. Hyland, K. (2000)' Model of Abstract

\begin{tabular}{ll}
\hline Moves & Function \\
\hline 1. Introduction & Establishes context of the paper and motivates the research \\
2. Purpose & Indicates purpose, outlines the aim behind the paper. \\
3.Method & Provides information on design, procedures, data analysis, etc. \\
4. Product & Indicates results and the argument, \\
5. Conclusion & points to applications or wider implications and Interpretation scope of paper \\
\end{tabular}

\subsection{Procedure}

At the beginning, $80 \mathrm{RA}$ abstracts from two disciplines in two languages were randomly chosen from recent published leading journals. In the analysis of the texts, first we examined the rhetorical structure of abstracts by examining the overall textual organization of each abstract as shown in Table 2, following Hyland's (2000) model. As discussed by Ackland (2009), the recognition of moves and the setting of move borders in abstracts were realized through two methods, one was based on top-down" approach that is the content of the abstract, and the other one is bottom-up" approach based on linguistic signals. In this study, the textual boundaries of these units were identified primarily on the basis of semantic criteria, that is, the "top-down" approach. Then frequency of each move in each discipline was calculated and compared with its counterpart.

The recognition of each move in the data sets was quite straightforward on the whole. In summary, the overall organization of the RA abstracts was analyzed based on Hyland's (2000) five-move model. Then, discovered moves and steps were compared to find similarities and differences in move structure of abstracts in two discipline and languages.

\section{Result}

This research discusses the variation in rhetorical structure and linguistic features of RA abstracts across languages and across disciplines. The cross-linguistic analyses are conducted in two languages: English and Persian, and the cross disciplinary analyses are conducted on RA abstracts in two fields: linguistics that belongs to the social science or as Hyland, (2000) called "soft discipline" and mathematics, which is a natural science or hard discipline. This part reports the results of these two kinds of analyses

\subsection{Cross linguistic analysis of linguistics abstracts}

Hyland (2000) determined that more than 95 percent of the abstracts had all five moves in his study on more than 800 abstracts. In line with his finding, in this study, most of the linguistics abstracts only have four basic structural components: the purpose move (M2), the method move (M3), the product move (M4) and the conclusion move (M5) in both English and Persian, as shown in Table 3. The M2-M3-M4-M5 pattern came out as the conventional schema in the abstracts in both languages.

Table 3. Frequency of the Occurrence of Moves in the Linguistic Abstracts

\begin{tabular}{lll}
\hline Moves & English & Persian \\
\hline 1. Introduction & $40 \%$ & $20 \%$ \\
2. Purpose & $100 \%$ & $100 \%$ \\
3.Method & $100 \%$ & $100 \%$ \\
4. Product & $100 \%$ & $100 \%$ \\
5. Conclusion & $100 \%$ & $70 \%$ \\
\hline
\end{tabular}

The results in Table 3 show that the purpose move (M2), the method move (M3) and the product move (M4) are the most frequent and obligatory moves in both groups of abstracts. Such findings are in line with those of Santos's (1996) with the purpose move and the method move occurring in almost all the abstracts. In contrast, the other two moves, the introduction move (M1) and the conclusion move (M5) occur less frequently.

The majority of the abstracts follow the same sequence of rhetorical structure: 
M1-M2-M3-M4-M5. However, the post-posing of M1 results in a reordering of the move pattern. Therefore; the first null hypothesis which indicates that "there is no difference between type and frequency of move structure in research article abstracts written by English native and non-native (Iranian) students in applied linguistics" was confirmed.

Table 4.Frequency of the Occurrence of Moves in the Mathematic Abstracts

\begin{tabular}{lll}
\hline Moves & English & Persian \\
\hline 1. Introduction & $20 \%$ & $10 \%$ \\
2. Purpose & $80 \%$ & $10 \%$ \\
3.Method & $100 \%$ & $100 \%$ \\
4. Product & $30 \%$ & $100 \%$ \\
5. Conclusion & $50 \%$ & $80 \%$ \\
\hline
\end{tabular}

Generally, the five moves are present to some degree in mathematics abstracts.

Move frequency is shown in Table 4: the introduction move (M1) is the least frequent in both groups of abstracts (20\% in English, $10 \%$ in Persian); the method move (M3) is found in $100 \%$ of the analyzed abstracts; the frequency of occurrence of the purpose move (M2) (80\% in English, 10\% in Persian), the product move (M4) (30\% in English, 100\% in Persian) and the conclusion move (M5) (50\% in English, $80 \%$ in Persian) vary greatly across languages. The analysis revealed a strong tendency to omit the purpose move in the Persian abstracts (10\% of the cases contain M2), and the product move in the English abstracts (30\% of the cases contain M4); the difference in the conclusion move is relatively less significant (50\% in English, 80\% in Persian).

The language use influences the frequency of the occurrence of the moves. The results in Table 4 show that the mathematics RA abstracts in English basically follow a M2-M3 pattern, and the mathematics RA abstracts in Persian have the M3-M4-M5 structure as the conventional schema. So the first null hypothesis which indicates that" there is no difference between type and frequency of move structure in research article abstracts written by English native and nonnative (Iranian) students in Mathematics" was rejected. As it was mentioned in this filed both native and non-native writers did not follow the common conventional scheme given by Hyland(2000).

\section{Summary of cross-linguistic analysis}

The cross-linguistic analysis on linguistics RA abstracts showed that all the abstracts fundamentally followed an M2-M3-M4-M5 pattern. The purpose move (M2) and the method move (M3) are obligatory in both sets of texts. While the result move (M4) and the discussion move (M5) were fairly common in English abstracts, the same could not be said for Iranian abstracts. The Introduction move (M1) was the least frequent move in abstracts from both journals. A striking difference in the rhetorical structure was identified in the product move (M4). M4 was a final move in Iranian RA abstracts but never in English RA abstracts.

The rhetorical structure analysis on mathematic abstracts in English and Persian demonstrated that abstracts in English basically followed a M2-M3 pattern, but those in Persian had a different structure, that was, M3-M4-M5. The method move (M3) was the only obligatory move in the mathematic abstracts in both languages. Similar to the findings in Linguistics, the introduction move (M1) is the least frequent move. The most significant differences lied in the frequency of the occurrence of the purpose move (M2), the product move (M4) and the conclusion move (M5). English abstracts were more likely to include M2 but Persian abstracts contained M4 and M5 more often.

The analyses revealed that less promotion was used in the Persian abstracts. This may be attributed to the relatively small discourse community in the Persian academic world. It may also points to a cultural distinction because in the Persian culture, authors are not encouraged to promote their studies.

\subsection{Cross-disciplinary analysis of abstract}

In this section, cross-disciplinary analysis was conducted in order to identify the variations of RA abstracts in terms of rhetorical structure across disciplines. Table 5 shows the frequency of different moves in both disciplines. The introduction move (M1) was the least frequent move in both sets of RA abstracts; the method move (M3) was the most frequently occurring section in all RA abstracts. The conclusion move (M5) was found more frequently in linguistics RA abstracts, the frequency of the occurrence of purpose move (M2) and product move (M4) showed great variations according to the discipline.

Table 5. Summary of Move Frequency

\begin{tabular}{lllllll}
\hline Moves & linguistics & \multicolumn{3}{l}{ mathematics } & Average \\
\cline { 2 - 6 } & English & Persian & English & Persian & linguistics & mathematics \\
1. Introduction & $8(40 \%)$ & $4(20 \%)$ & $4(20 \%)$ & $2(10 \%)$ & $6(30 \%)$ & $3(15 \%)$ \\
2. Purpose & $20(100 \%)$ & $20(100 \%)$ & $16(80 \%)$ & $2(10 \%)$ & $20(100 \%)$ & $9(45 \%)$ \\
3.Method & $20(100 \%)$ & $20(100 \%)$ & $20(100 \%)$ & $20(100 \%)$ & $20(100 \%)$ & $20(100 \%)$ \\
4. Product & $20(100 \%)$ & $20(100 \%)$ & $6(30 \%)$ & $20(100 \%)$ & $20(100 \%)$ & $13(60 \%)$ \\
5. Conclusion & $20(100 \%)$ & $20(100 \%)$ & $10(50 \%)$ & $16(80 \%)$ & $17(85 \%)$ & $13(60 \%)$ \\
\hline
\end{tabular}


It was discovered that the most frequent move structure in linguistics was M2-M3- M4-M5 (85\% of the cases); however, no conventional structure could be determined in mathematic: Persian mathematicians usually followed the M3-M4-M5 structure ( $80 \%$ of the cases), whereas English mathematicians commonly preferred the M2-M3 model ( $80 \%$ of the cases). This phenomenon may be due to the disciplinary variations. Mathematic, as an old and mature discipline, has existed and been studied for many years in Persian and Anglo-American academic communities. Therefore, mathematicians in both countries seemed to have developed their own unique academic writing norms. However, linguistics, especially applied linguistics, is a relatively new discipline in Iran, and the majority of the RA abstracts in my study are about English teaching. It would not be surprising if Persian linguists have been greatly influenced by the English authors in this field, and usually follow the rhetorical norms established by English writers.

\section{Discussion}

The results of the study indicated that variation in writing can be found at different levels of texts across disciplines and languages. The key difference in the cross-disciplinary comparison of RA abstracts set in the textual structure. Based on Hyland's (2000) framework, linguistic RA abstracts basically go along with the international convention based on the patterns of the English academic discourse community M2-M3-M4-M5 pattern. While mathematic RA abstracts do not take a normal structure, international writers follow a M2-M3 format, and Persian writers follow a M3-M4 structure. According to Hyland (2003) the moves or steps with sixty and more percent rates can be considered as obligatory and less than sixty percent is called optional which used as a role for providing the preceding pattern.

The method move was present in every abstract and thus is the only obligatory move in both disciplines. This indicates that describing the methodology of the study is an important part of the abstracts in these two disciplines. However, the use of the method move displayed some disciplinary differences in the abstracts. The method move (M3) in mathematics abstracts appeared in the form of an independent move, but 25 percent of the M3s in linguistic abstracts were entrenched within the purpose move (M2) in a packed form, so mathematic abstracts were more probable to offer more space to M3 than linguistics abstracts. This demonstrates that the emphasis of the mathematic abstracts lies mainly in the method move.

The comparison of the move-step structure of RA abstracts in two languages showed that English abstracts were more likely to include the canonical moves while there were more move omissions in Persian abstracts. Although usually Persian abstracts were longer than English ones on average, Persian authors had a stronger predisposition to neglect one or more moves in abstract writing. In linguistics abstracts, no significant difference in rhetorical structure was recognized. Basically, Persian authors followed the international structure in terms of moves, although English abstracts included the conclusion move (M5) more frequently than Persian abstracts.

A noticeable difference was uncovered in mathematic abstracts. The purpose move (M2) was rather usual in English abstracts, while the same could not be said for Persian abstracts.

The product move (M4) was much more repeatedly used in Persian abstracts than in English abstracts. English writers liked offering their results earlier by containing results of the study in M2 or pre-posing M4 as the initial move; however, Persian writers favored recounting the results in the product move rather than foregrounding the product of the study in M2. M2 and M4 accomplished an overlapping function in specific English abstracts. In other words M2 was a prominent move in English RA abstracts, but not in Persian RA abstracts. However, M4 seemed more frequently in Persian RA abstracts than in English RA abstract.

These genre differences may be ascribed to the size of the Persian academic discourse society and certain characteristic of Persian culture. The essential function of abstracts is to improve the study to bigger readerships. The traditional values in Persian culture, such as Persian writers usually favored writing in an indirect way to in a direct way, may encumber the promotion function of abstracts. On the contrary, English authors have to encounter more challenging rivalry in the bigger international community, and have to try to "stand out" in their academic community. This study is in line with findings of some previous studies such Martin (2003) that investigated abstracts written in English and Spanish in social science. The findings revealed that the rhetorical structure of abstracts written in Spanish in the area of experimental social sciences generally reflects the international scheme; however, some degrees of differences in move two was observed. Moreover; Salvager-Meyer (1990) endeavored 77 medical English abstracts of three text types of case reports, research papers and review articles. He identified six moves for the generic organization of a medical research article abstract

This study also suffers from some limitations. Among many disciplines just two disciples of applied linguistics and mathematics were chosen and, because of availability, Iranians as non-native writers were selected, moreover; other parts of the articles were not included since the manageability got under question.

\section{Implication}

The results of the study have pedagogical implications to aid students, particularly non-native writers and post-graduate students in their academic writing. Bhatia (1997) revealed that genre analysis is able to provide valuable information to novice authors by exposing them to the conventions of a particular genre, and they will be able to investigate and create more complex genres as they obtain genre knowledge .Hyland (2002) affirmed that the mastery of genre knowledge would contribute students in becoming participants of their disciplinary community. Loi and Evans (2010) declared that with the knowledge of genre practices, novice writers may not only produce more complex genres based on genre patterns but also get long term benefits from the explicit knowledge of genre conventions because genre knowledge will provide learners with a thorough and complete understanding of certain texts. They further affirmed that ESP teachers 
or the university writing teachers may choose RAs or parts of RA to show the macrostructure of the genre and debate the function of each move and/or steps with students' contribution.

The results from the cross-disciplinary analysis in the study can be a guide in helping students to recognize disciplinary variations in terms of moves, the linear sequence, and the function of each move in abstract writing. The knowledge obtained from the cross-linguistic analysis has displayed how move step analysis is a valuable analytical tool for understanding cultural differences in the rhetorical structure of RA abstracts. The rhetorical structure of English academic writing will become more observable to Persian authors because they will understand the expectations of native English readers as well as they acquire the knowledge of the different rhetorical characteristics in English and Persian. Teaching the typical rhetorical structure of an RA abstract (e.g., Swales \& Feak, 2009) to students, especially to nonnative authors, would help them identify these specific characteristics of each move and how moves are used in writing. ESP writing instructors should be aware that the preferred rhetorical strategies in both languages are different, and guide non-native authors writing to produce academic discourse following the norms of the international academic community.

\section{References}

Ackland, G. M. (2009). A discourse analysis of English and French research article abstracts in linguistics and economics. San Diego, CA: Montezuma Publishing.

Atai, M.R.(2007). Genre Analysis : An investigation of the structure of research article results \& discussion and colocation frameworks in medical research Articles. Proceedings of the $6^{\text {th }}$ International AELFE Conference : Teaching and Learning LSP : Blurring the Boundaries. ISCAL, Lisboa, Portugal.

Bhatia, V.K. (1993). Analyzing Genre: Language Use in Professional Settings [M]. London \& NY: Longman.

Bhatia, V. K. (1997). Introduction: Genre analysis and world English. World English, 16(3), 313-319.

Giannoini, D, S. (2002).Words of gratitude: A contrastive study of acknowledgement texts in English and Italian research articles. Applied Linguistics, 23(1)1-31.

Golpour Lasaky, F.(2011). A contrastive study of generic organization of doctoral dissertation acknowledgements written by native and non-native (Iranian) students in applied linguistics. Modern Journal of Applied Linguistics, 3( 2), 175-200

Hyland, K. (1996). Talking to the Academy: Forms of hedging in science research articles. Written Communication, 13(2), 251-281.

Hyland, K. (2000). Disciplinary discourses: Social interactions in academic writing. London, UK: Longman.

Hyland, K. (2002). Options of identity in academic writing. ELT Journal, 56(4), 351-358.

Hyland, K. (2003). Self-citation and self-reference: Credibility and promotion in academic publication. Journal of the American Society for Information Science and Technology, 54(3), 251-259.

Lim, J. M. H. (2006). Method sections of management research articles: A pedagogically motivated qualitative study. English for Specific Purposes, 25(3), 282-309.

Loi, C. K., \& Evans, M. S. (2010). Cultural differences in the organization of research article introductions from the field of educational psychology: English and Chinese. Journal of Pragmatics, 42(10), 2814-2825.

Nwogu, K, N. (1997).The medical research paper: structure and function. English for Specific Purposes,16(2),119-137.

Martin, P. M. (2003). A genre analysis of English and Spanish research paper abstracts in experimental social sciences. English for Specific Purposes, 22,223-43.

Peacock, M. (2002). Communicative move in discussion section of research articles. System, 30,479-497.

Pho, P. D. (2008). Research article abstracts in applied linguistics and educational technology: A study of linguistic realizations of rhetorical structure and authorial stance. Discourse Studies, 10(2), 231-250.

Salager-Meyer, F. (1992) A text-type and move analysis study of verb tense an modality distribution in medical English abstracts. English for Specific Purposes, 11(2), 93-113.

Samraj, B. (2002). Disciplinary variation in abstracts: The case of wildlife behavior and conservation biology. In J. Flowerdew (Ed.), Academic discourse (pp. 105-120). New York, NY: Longman.

Samraj, B. (2005). An exploration of a genre set: Research article abstracts and introduction in two disciplines. English for Specific Purposes, 24(2), 141-156.

Santos, M. B. D. (1996). The textual organization of research paper abstracts in applied linguistics. Text, 16(4), 481-499.

Swales, J. M. (1987). Aspects of article introductions. Birmingham, England: Language Studies Unit, University of Aston.

Swales, J. M. (1990). Genre analysis: English in academic and research settings. Cambridge, UK: Cambridge University Press. 
Swales, J. M. (2004). Research genres: Explorations and applications. Cambridge, UK: Cambridge University Press.

Swales, J. M., \& Feak, C. B. (2009). Abstracts and the writing of abstracts. Ann Arbor, MI:University of Michigan Press.

Taylor, G., \& Chen, T. (1991). Linguistic, cultural, and subcultural issues in contrastive discourse analysis: Anglo-American and Chinese scientific texts. Applied Linguistics, 12(3), 319-336.

Yang, R. Y, \& Allison, D. (2003). Research articles in applied linguistics: Moving from results to conclusions. English for Specific Purposes, 22(4), 365-385. 